\title{
Post conflict water management: learning from the past for recovery planning in the Orontes River basin
}

\author{
Myriam Saadé-Sbeih $^{1}$, François Zwahlen ${ }^{2}$, Ahmed Haj Asaad ${ }^{1}$, Raoul Gonzalez ${ }^{1}$, and Ronald Jaubert ${ }^{1}$ \\ ${ }^{1}$ Graduate Institute of International and Development Studies, Chemin Eugène-Rigot 2, \\ 1202 Geneva, Switzerland \\ ${ }^{2}$ Centre for Hydrogeology and Geothermics (CHYN), University of Neuchâtel, Rue Emile-Argand 11, \\ 2000 Neuchâtel, Switzerland \\ Correspondence to: Myriam Saadé-Sbeih (myriam.saade@gmail.com) \\ Published: 17 October 2016
}

\begin{abstract}
Water management is a fundamental issue in post-conflict planning in Syria. Based on historical water balance assessment, this study identifies the drivers of the profound changes that took place in the Lebanese and Syrian parts of the Orontes River basin since the 1930s. Both drastic effects of the conflict on the hydro-system and the strong uncontrolled anthropization of the river basin prior to the crisis have to be considered in the design of recovery interventions.
\end{abstract}

\section{Introduction}

Current human-hydrosystem interactions are shaped by past water uses, hydraulic development and hydro-social configurations (Swyngedouw, 2009). Historical reconstruction of water use is considered a powerful approach to identify drivers of changes in human-water relationships in order to design realistic future water management scenarios and relevant policies (Grouillet et al., 2015; Lu et al., 2015). While general trends such as population growth or increase of irrigated areas have been considered as major drivers of changes, little attention has been paid to radical changes, for example in the case of armed conflicts. In those cases, evidence-based decision making is requested for sound emergency interventions and post-conflict planning. However, decision makers are faced with poor and asymmetric information challenging their ability to define appropriate responses (Gibson et al., 2005).

\section{Study area}

The transboundary Orontes (Al Asi) River basin, shared between Lebanon, Syria and Turkey, is representative of the global changes in water use that impacted hydrosystems during the last century in the southern and eastern parts of the
Mediterranean basin. Since the 1950s and especially in the 1990s, the area witnessed an intensive surface and ground water development, mostly for agricultural purposes, leading to a sharp decrease in the river discharge in the middle course of the basin; the drying up of numerous springs and localized groundwater overexploitation in several areas (Zwahlen et al., 2014). After the outbreak of the Syrian crisis in 2011, the study area is a key region in the conflict (Haj Asaad and Jaubert, 2014) and witnessed a drastic spatial redistribution of the water consumption and a radical reconfiguration of surface and ground water flows. As a consequence of the decrease in water consumption in the middle reach of the basin, the Orontes River discharge increased by two-fold at the Syrian-Turkish border in 2014; whereas water consumption increased in "shelter" areas, where displaced populations have taken refuge.

\section{Method}

This study aims to provide guidance for recovery planning in the post conflict transition period in the Lebanese and Syrian parts of the Orontes River basin. It identifies through a historical water balance assessment, the socioeconomic drivers (Reynard et al., 2014) of the profound changes that took place at the regional catchment level. The multidisciplinary 

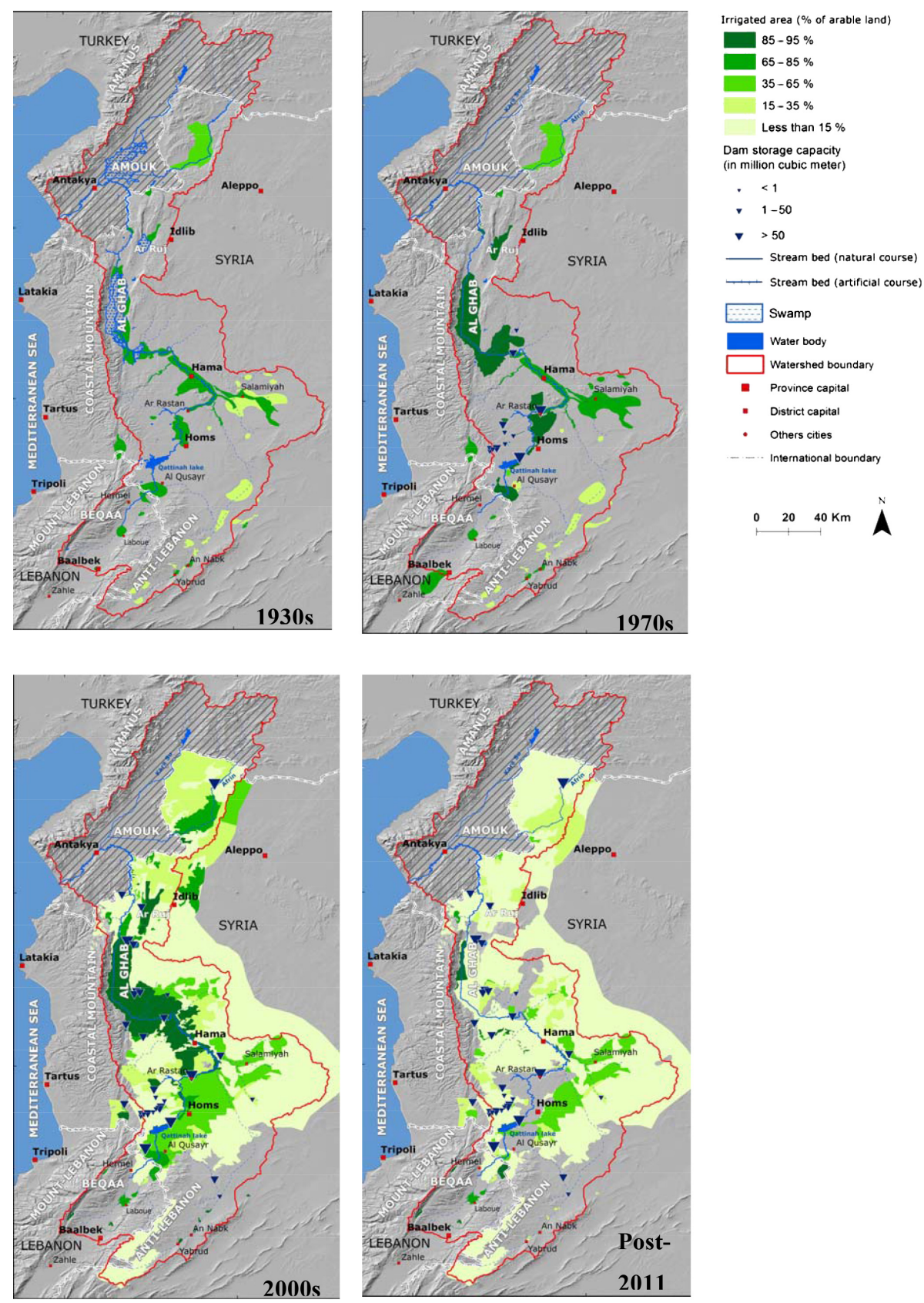

Figure 1. Evolution of irrigated areas for the 1930s; 1970s; 2010s and after 2011.

approach consists of assessing the human-hydrosystem coevolution through the calculation of water balances at two scales for four representative periods in terms of water exploitation: the 1930s; 1970s; 2000s and post-2011. The lack of accurate and comprehensive long term datasets is tackled by confronting different estimation methods of historical surface and ground water flows: literature reviews, historical records, statistical analysis, expert interviews, maps and satellite images analysis to assess land use changes. Water balance, as a synthesis tool, is used to check the plausibility of the estimated parameters.

\section{Transformation of the hydro-system between the 1930 s and the 2000s}

In terms of magnitude, irrigation is the main driver of changes in the Orontes River basin water balance: in the last century, water consumption has been significantly modified by an intensive anthropization, especially the development of 

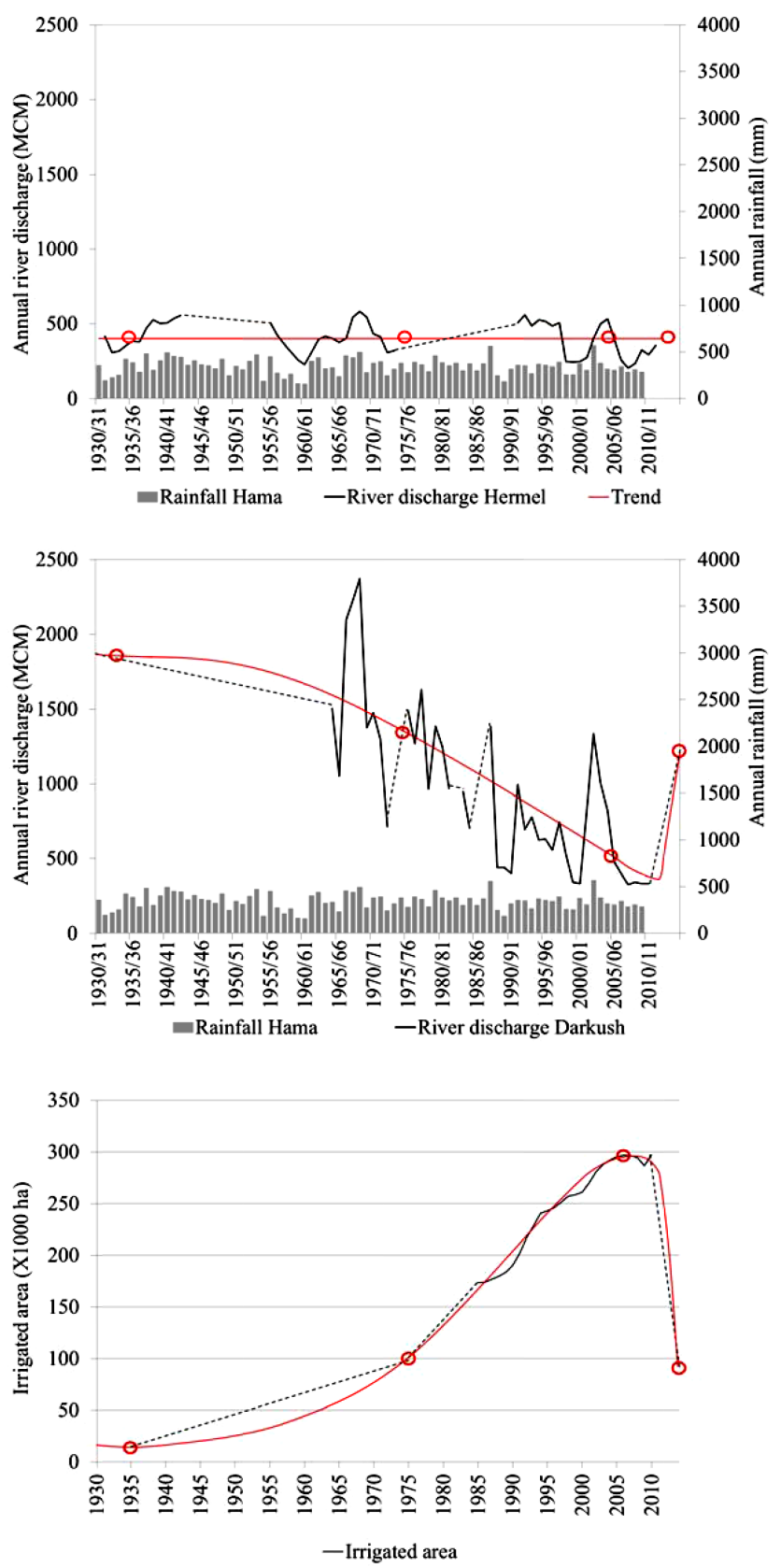

Figure 2. Changes in river discharge and irrigated areas 1930/1931-2013/2014. River discharge series from UN-ESCWA and BGR (2013).

irrigation (Fig. 1). The caused by human activities increased by a factor 9 between the 1930s and the 2000s (from 235 to $2210 \mathrm{MCM} \mathrm{yr}^{-1}$ ), with an increase in consumption by a factor 5 between the 1930s and the 1970s; and about a factor 2 (1.8) between the 1970s and the 2000s (Fig. 2).

As a consequence, the Orontes River discharge decreased sharply in the downstream part of the basin: at the Darkush gauging station, the annual discharge decreases from $1850 \mathrm{MCM} \mathrm{yr}^{-1}$ in the 1930 s to 1250 in the 1970 s and 600 in the 2000s. According to our last and more fitting water balance reconstitutions, a first negative variation of the groundwater storage is estimated for the 1970s, with localized groundwater extraction in the Salamyah and Karnaz areas. Then an important variation of the storage is estimated in the 2000s ( $-155 \mathrm{MCM} \mathrm{yr}^{-1}$ for the global basin) due to generalized intensive groundwater extraction in different parts of the study area: mainly Al Qaa - Qusayr area in the Muhardah sub-catchment $\left(-50 \mathrm{MCM} \mathrm{yr}^{-1}\right)$, North Muhardah area in the Jisr ash Shughur sub-catchment $\left(-85 \mathrm{MCM} \mathrm{yr}^{-1}\right)$ and ar Ruj area in the Darkush sub-catchment $\left(-20 \mathrm{MCM} \mathrm{yr}^{-1}\right)$.

The assessment at different temporal and spatial scales shows that each sub-catchment has different dynamics and evolution trends. The upstream sub-catchment remained relatively stable during the last century. The downstream subcatchments faced major changes in terms of surface and ground water flows and storage: a sharp decrease in river and spring discharges and localized negative variation of groundwater storage (Fig. 3). For example, in the Jisr ash Shughur sub-catchment, $54 \%$ of the total average inflow in the 1930 s was provided by surface water (direct runoff or river discharge), it decreases to $43 \%$ in the 1970 s and to $36 \%$ in the 2000s. Future water management policies have to consider irrigation as a main target and to be adapted to the specific conditions of each sub-catchment.

\section{Drastic changes after 2011}

The Syrian crisis led to a drastic redistribution of water use patterns and a sharp decrease in water consumption for irrigation, because of combats, population displacement, destruction of water infrastructures and the lack of energy and agricultural inputs. In the first years of the crisis water consumption fell by a factor 3.3 (from 2240 to $670 \mathrm{MCM} \mathrm{yr}^{-1}$ ), the river discharge increased in the downstream part, by 2 -fold at the Syrian-Turkish border. A positive variation in groundwater storage is estimated for downstream subcatchments. There is a disintensification of water consumption at large scale, but it should be noticed that, in some places, there is a local intensification of water consumption (Al Qaa area for example).

\section{Conclusions}

Water management is a fundamental element in post-conflict planning in Syria and the Orontes River basin. To design relevant water recovery program and policy and prevent water mismanagement, decision makers will have to consider the drastic effects of the conflict on the hydro-system since 2011, as well as the strong uncontrolled anthropization of the river basin prior to the crisis. They should take into consideration expected drivers, such as irrigation and energy policies, as well as unexpected drivers, such as the political crisis. As- 


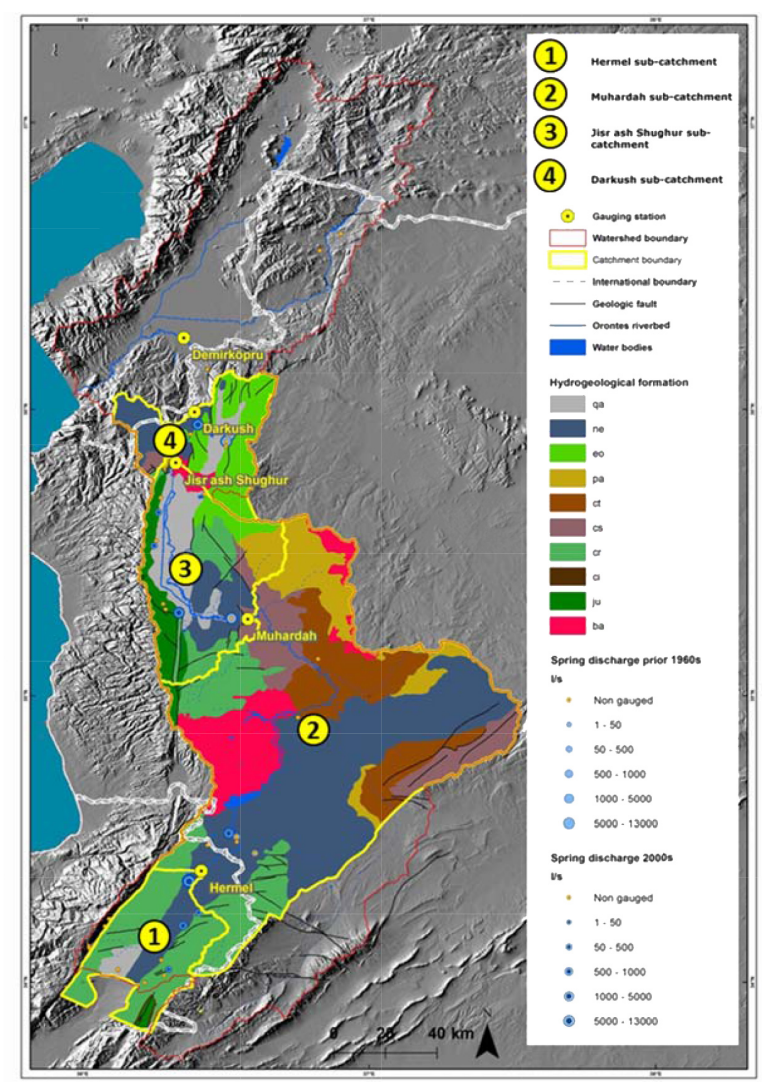

Global catchment - main water balance components

\begin{tabular}{lr} 
Precipitation & $455 \mathrm{~mm}$ \\
Evapotranspiration & $265 \mathrm{~mm}$ \\
Effective precipitation & $189 \mathrm{~mm}$ \\
\hline Catchment area & $4813 \mathrm{~km}^{2}$
\end{tabular}
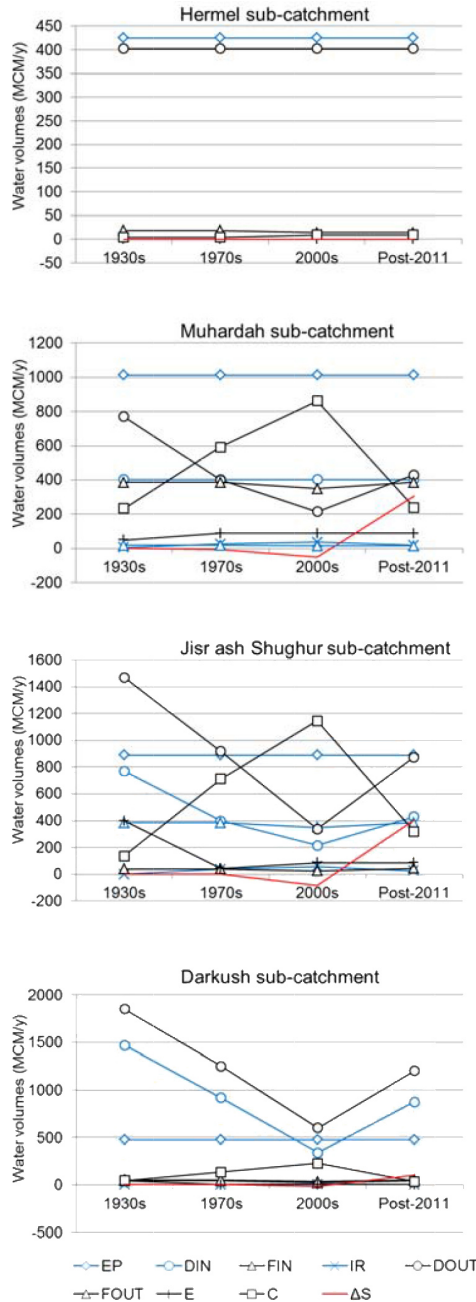

Figure 3. Historical water balance in the Lebanese and Syrian parts of the Orontes River basin. EP: Effective precipitation; DIN: River discharge (inflow); FIN: Ground water or surface water inflow; DOUT: River discharge (outflow); FOUT: Ground water or surface water outflow; $E$ : Water surface evaporation; $C$ : Anthropic evapotranspiration; $\Delta S$ change in groundwater storage.

sessing present and past situations is a precondition to design sound policies.

\section{Data availability}

For Fig. 2, data are coming from the following sources:

River discharge series from UN-ESCWA and GBR (2013) http://waterinventory.org/sites/waterinventory.org/ files/chapters/Chapter-07-Orontes-River-Basin-web_1.pdf.

Irrigated areas based on NAPC Syrian Agriculture Database http://www.agriportal.gov.sy/napcsyr/sadb.htm.

For Figs. 1 and 3, the methodology and data sets will be detailed in further publications and made available on the Orontes Project website https://www.water-security.org/ (planned to be available beginning of next year).
Acknowledgements. This study is part of the Orontes River Basin Research Program led by the Graduate Institute of International and Development Studies with the support of the Swiss Development and Cooperation Agency. It aims to provide baseline elements to support emergency interventions and post-conflict planning in Syria and to contribute to coordinated management of the Orontes River Basin's shared water resources in the long term (Jaubert et al., 2014). The study is funded by the Swiss Federal Department of Foreign Affairs.

\section{References}

Gibson, C. C., Andersson, K., Ostrom, E., and Shivakumar, S.: The Samaritan's Dilemma: The Political Economy of Development Aid, Oxford University Press, 288 p., 2005.

Grouillet, B., Fabre, J., Ruelland, D., and Dezetter, A.: Historical reconstruction and 2050 projections of water de- 
mand under anthropogenic and climate changes in two contrasted Mediterranean catchments, J. Hydrol., 522, 684-696, doi:10.1016/j.jhydrol.2015.01.029, 2015.

Haj Asaad, A. and Jaubert, R.: Geostrategic stakes and the impact of the conflict in the Orontes River basin, Confluences méditerranée, 89, 173-184, doi:10.3917/come.089.0173, 2014.

Jaubert, R., Saadé-Sbeih, M., Al Dbiyat, M., and Haj Asaad, A.: E-Atlas of the Orontes River basin, https://www.water-security. org/, 2014.

Lu, Z., Wei, Y., Xiao, H., Zou, S., Xie, J., Ren, J., and Western, A.: Evolution of the human-water relationships in the Heihe River basin in the past 2000 years, Hydrol. Earth Syst. Sci., 19, 22612273, doi:10.5194/hess-19-2261-2015, 2015.

Reynard, E., Bonriposo, M., Graefe, O., Homewood, C., Huss, M., Kauzlaric, M., Liniger, H., Rey, E., Rist, S., Schädler, B., Schneider, F., and Weingartner, R.: Interdisciplinary assessment of complex regional water systems and their future evolution: how socioeconomic drivers can matter more than climate, Wiley Interdiscip. Rev. Water, 1, 413-426, doi:10.1002/wat2.1032, 2014.
SADB (Syrian Agriculture Database): http://www.agriportal.gov. sy/napcsyr/sadb.htm, last access: 9 September 2014.

Swyngedouw, E.: The Political Economy and Political Ecology of the Hydro-Social Cycle, J. Contemp. Water Res. Educ., 142, 5660, doi:10.1111/j.1936-704X.2009.00054.x, 2009.

UN-ESCWA and BGR (United Nations Economic and Social Commission for Western Asia; Bundesanstalt für Geowissenschaften und Rohstoffe), Inventory of Shared Water Resources in Western Asia, Beirut, 2013.

Zwahlen, F., Bakalowicz, M., Gonzalez, R., Haj Asaad, A., SaadéSbeih, M., and Jaubert, R.: Groundwater flows in the Orontes River basin and groundwater in the Syria-Lebanon water sharing agreement, International Association of Hydrogeologists, Selected Papers on Hydrogeology, 53-62, 2016. 